\title{
Análise das Margens e Transmissão de Preços no Sistema Agroindustrial do Suco de Laranja no Brasil
}

\author{
Adelson Martins Figueiredo ${ }^{1}$, Hildo Meireles de Souza Filho ${ }^{2}$ \\ e Luiz Fernando de Oriani Paullilo ${ }^{3}$
}

Resumo: As relações econômicas entre citricultores e empresas processadoras de suco de laranja no Brasil têm sido marcadas por conflitos, culminando em denúncias de descumprimento de cláusulas contratuais e abertura de processos junto ao Conselho Administrativo de Defesa da Concorrência (Cade). As recentes tentativas frustradas de formação de um Consecitrus evidenciam que os conflitos permanecem. Devido à evidente fragilidade nas relações entre esses agentes, o objetivo desse trabalho foi investigar se há indícios de uso de poder de mercado por parte das empresas processadoras em suas transações com produtores de laranja. Para isso, examina-se a evolução das margens brutas de comercialização e a transmissão de preços, a partir de dados mensais de preços de laranja e preços de suco de laranja no período de janeiro de 2001 a março de 2011. Do estudo das margens constatou-se que os ganhos obtidos pelas processadoras são significativamente maiores quando se adiciona a venda de subprodutos do processamento da laranja. Destaca-se que, em geral, as margens brutas do elo de processamento são subestimadas quando se consideram apenas os produtos principais no cálculo. A análise de transmissão demonstrou que as empresas processadoras repassam apenas decréscimos de preço para produtores no curto prazo e que há assimetria no longo prazo. Portanto, há indícios do uso de poder de mercado por parte das empresas processadoras de suco de laranja, sendo que essa prática pode gerar perdas acumuladas aos produtores, uma vez que há assimetria no longo prazo com recomposição menos que proporcional à variação dos preços.

Palavras-chaves: Mercados imperfeitos, margens de comercialização, transmissão de preços, suco de laranja, mercado de laranja.

1 Professor do Departamento de Economia, Universidade Federal de São Carlos, campus Sorocaba. E-mail: adelson@ufscar.br

2 Professor do Departamento de Engenharia de Produção, Universidade Federal de São Carlos, campus São Carlos. E-mail: hildo@dep.ufscar.br

3 Professor do Departamento de Engenharia de Produção, Universidade Federal de São Carlos, campus São Carlos. E-mail: dlfp@power.ufscar.br 
Abstract: Trades between orange growers and orange juice processing companies in Brazil have been characterized by conflicts, culminating in accusations of breach of contracts and cases of anti-trust violations in the Council for Economic Defense (Cade). Recently, attempts to create a council, called Consecitrus, have failed, evidencing that conflicts remain. Due to the evident fragility of the transactions between these agents, the aim of this study is to investigate whether there is indication of market power use by the processing companies in their dealings with growers. For this, the evolution of gross margins and price transmission are analyzed. The analysis of the margins revealed that the gains achieved by processors are significantly higher when the revenue obtained with the sale of byproducts is added to the juice revenue. It was found that the margins are underestimated when considering only the leading products in its calculation. The analysis of price transmission showed that processing companies transfer price decreases for growers in the short-term and an asymmetry in the long-run. Therefore, there is an evidence of the market power use by orange juice processing companies, and this practice can generate cumulative losses for growers, since there is an asymmetry in the long-term with less than proportional price recovery.

Key-words: Imperfect markets, marketing margins, price transmission, orange juice, orange market.

Classificação JEL: D43.

\section{Introdução}

As relações entre citricultores e as empresas processadoras de suco de laranja no Brasil têm sido conflituosas, com denúncias de descumprimento de cláusulas contratuais e de uso de poder de mercado. Em 1995, empresas processadoras assinaram um Termo de Cessação de Conduta anticoncorrencial, determinado pelo Conselho Administrativo de Defesa Econômica (Cade), quando foi estabelecido o fim do contrato padrão. Em 2004, a Polícia Federal fez uma operação de apreensão de documentos, conhecida como Operação Fanta, recolhendo supostas provas de que o conluio entre empresas processadoras para fixação de preços ao produtor de laranja não havia se extinguido (PAULLILO e ALMEIDA, 2009). Em 2011 e 2012, fracassaram as negociações entre representantes da citricultura e da indústria com o objetivo de formar o Conselho dos Produtores de Laranja e das Indústrias de Suco de Laranja (Consecitrus) nos moldes Consecana ${ }^{4}$, evidenciando que os conflitos ainda permaneciam.

4 O Consecana estabeleceu um sistema de formação do preço da cana-de-açúcar baseado em critérios de qualidade, custos e preço dos produtos acabados da cadeia produtiva (açúcar e álcool) (ver CONSELHO DOS PRODUTORES DE
Observa-se uma crescente concentração da produção em propriedades maiores e a redução da participação dos pequenos e médios produtores, principalmente na produção e no número de imóveis (PAULILLO, 2006). Essa tendência tem sido acompanhada pelo crescimento da verticalização, com o plantio de pomares por parte das próprias empresas produtoras de suco. Azevedo (1996) fez exaustiva revisão da literatura existente sobre o papel da formação de pomares próprios no Sistema Agroindustrial Citrícola. O autor constatou que a formação de pomares próprios por parte da indústria citrícola no Brasil tem um papel mais importante em termos de ganho de poder de barganha junto a produtores independentes de laranja do que em termos de ganhos de eficiência. Ressalta-se que, em 2011, o relator do Cade no processo de fusão entre as empresas Fisher S.A. Comércio, Indústria e Agricultura e Citrovita Agro Industrial Ltda. aceitou que o relativo poder de compra das empresas processadoras de suco aliado à verticalização pode trazer prejuízos aos produtores. Em seu voto, o relator informa que o HHI (Índice de Herfindahl-

CANA-DE-AÇÚCAR, AÇÚCAR E ÁLCOOL DO ESTADO DE SÃO PAULO, 2006). 
Hirschman) calculado para o mercado de compra de laranja foi muito superior a 1.500 pontos. A soma das participações das quatro maiores empresas nesse mercado já era elevada antes da fusão e o HHI aumentaria ainda mais após a fusão ${ }^{5}$. Como solução para o problema e condição para aprovação da fusão entre as duas empresas, o Cade estabeleceu limitação aos pomares próprios das requerentes. Além do problema competitivo da verticalização da indústria processadora de laranja, o Cade reconheceu a argumentação de que a elevada assimetria de informação no setor reforça o poder de compra em relação aos citricultores, pois esses possuem menos informações sobre as condições de mercado do que a indústria, recomendando, também, restrições para a solução desse problema.

Considerando-se o exposto, esse artigo tem como objetivo examinar se há indícios de uso de poder de mercado por parte das empresas processadoras em suas transações com produtores de laranja, levando-se em conta a análise das margens brutas de comercialização e da transmissão de preços. Um dos grandes problemas nas investigações sobre o comportamento de mercado e uso de poder econômico é a necessidade de um grande volume de informações, que nem sempre são facilmente obtidas. Assim, nessa pesquisa, foram utilizados preços mensais de laranja e cotações de suco de laranja no período de janeiro de 2000 a março de 2011, que estão publicamente disponíveis. A metodologia utilizada implica em (1) examinar a evolução das margens brutas de comercialização entre os elos da produção de laranja e do processamento para a produção de suco e (2) analisar a transmissão de preços entre esses dois elos. Nesse último, pro-

5 Os valores estimados para a participação no mercado de compra de laranja das quatro maiores empresas (C4) e o índice de Herfindahl-Hirschman (HHI) são tratados como confidenciais no voto do relator. Pelo critério da Federal Trade Commission (FTC), também utilizado pelo Cade no Brasil, um HHI entre 1.500 e 2.500 indica Mercados Moderadamente Concentrados. Nossas estimativas indicam que o HHI, após a fusão, pode alcançar valor acima dos 2.500 pontos. Pelo critério da Federal Trade Commission (FTC), um HHI acima de 2.500 indica Mercado Altamente Concentrado. cura-se responder a três questões principais: (i) em que nível de mercado as variações dos preços têm origem e em que sentido essas variações se transmitem; (ii) com qual intensidade e durante que período se dá a transmissão; e (iii) se as transmissões dos acréscimos de preços são diferentes das dos decréscimos, ou seja, se existe assimetria na transmissão de preços. A análise é realizada a partir de séries históricas de preços recebidos pelos produtores de laranja e preços recebidos pelas empresas que produzem suco.

O referencial conceitual, a metodologia e os resultados encontram-se nas próximas seções. $\mathrm{O}$ artigo traz contribuições que podem ser úteis para a formulação de políticas públicas e para construção de um ambiente institucional capaz de promover o desenvolvimento dessa cadeia produtiva.

\section{Referencial conceitual}

Essa seção apresenta os conceitos básicos adotados na análise, dividindo-se em duas subseções: "margens de comercialização" e "transmissão de preços".

\subsection{Margens de comercialização}

A comercialização de matérias-primas e produtos acabados em uma cadeia agroindustrial assume dimensão vertical. Por exemplo, os produtores rurais vendem uma commodity para a indústria processadora, que agrega valor e vende um ou mais produtos para o varejo que, por sua vez, agrega mais valor e vende ao consumidor final. $\mathrm{O}$ valor agregado pelos agentes em cada estágio compreende os custos e o lucro. Há duas abordagens para a identificação e análise do valor agregado pelos agentes (AGUIAR, 2004). Na primeira, os custos de produção, transporte e comercialização são obtidos por diversos meios alternativos: balanços de empresas (Conta de Resultados que têm dados de custos), entrevistas com especialistas das cadeias, entrevistas com executivos de empresas e associações rurais, 
especialistas em agronegócios, custos calculados por pesquisadores, empresas de consultoria e instituições governamentais. Tais dados são difíceis de serem obtidos, principalmente se as empresas não são obrigadas a divulgar balanços e a não revelar informações de custos, como é o caso da indústria processadora de laranja no Brasil.

A segunda abordagem compreende um estudo das margens brutas de comercialização a partir dos preços observados nos mercados. Nesse caso, a análise da evolução das margens depende de informações sobre preços, mais fáceis de serem obtidas. A margem de comercialização é definida como sendo a diferença entre o preço pelo qual um agente vende uma unidade de um produto e o pagamento que ele faz pela quantidade equivalente de produto que precisa comprar para vender essa unidade. Por exemplo, a margem de uma empresa processadora de laranja seria a diferença entre o preço recebido por determinada quantidade de produto processado (por exemplo, o preço recebido por libra de sólidos contida no suco de laranja concentrado e congelado) e o preço recebido pelo citricultor pela quantidade de laranja necessária para produzir aquela mesma quantidade de produto processado. Vale notar que a margem, medida a partir da diferença entre dois preços, é determinada em dois mercados: o mercado de laranja e o mercado de suco de laranja. Em outras palavras, são as condições de oferta e de demanda nesses dois mercados que determinarão as margens.

A margem de comercialização pode ser também definida como "o preço de um conjunto de serviços de comercialização, o qual seria o resultado de uma demanda e de uma oferta por tais serviços" (AGUIAR, 2004). Os serviços de comercialização seriam aqueles relacionados com as diversas operações assumidas por um ou mais agentes em um determinado estágio do sistema, tais como classificação, processamento, armazenamento, transporte etc.

A margem, medida por meio da diferença de preços, compreende a soma do lucro e do custo com transformação e/ou com serviços. Como informações sobre custos e lucros são muito difí- ceis de serem obtidas, a mensuração da margem pela diferença de preços torna-se muito atraente.

\subsection{Transmissão de preços}

Estudos que investigam a transmissão de preços têm procurado respostas para três questões principais ${ }^{6}$. A primeira consiste em tentar identificar em que nível da cadeia as variações dos preços são originadas e em que sentido essas variações são transmitidas. Essa investigação tem sido feita por meio de testes de causalidade em modelos econométricos. Em sistemas agroindustriais, por exemplo, há forte predominância de variações originadas no mercado atacadista e na indústria processadora (AZEVEDO e POLITI, 2008; MAYORGA et al., 2007; FIGUEIREDO et al., 2010; AGUIAR e FIGUEIREDO, 2011). Variações de preços são transmitidas aos produtores rurais e ao varejo a partir desses segmentos.

A segunda questão diz respeito à intensidade e ao período de ocorrência da transmissão. Para medir a intensidade da transmissão, estima-se a elasticidade de transmissão de preços, ou seja, o impacto percentual de uma variação do preço em um segmento do sistema sobre o preço do outro segmento.

A terceira questão a responder é se as transmissões dos aumentos de preços são diferentes das transmissões das quedas. Se há diferença, tem-se o que se chama de assimetria na transmissão de preços. Essa assimetria é indicada pela ocorrência de duas diferentes elasticidades de transmissão: uma para aumento e outra para redução de preços. Entre as razões para sua existência está o exercício de poder de mercado. Por exemplo, um processador de produtos agropecuários poderia ampliar sua margem de lucro quando o preço do produto processado aumentasse. Nesse caso, ele não repassaria todo o aumento do preço para os produtores rurais. Em condições de queda no preço, ele procuraria transmitir toda sua perda para o segmento abaixo na cadeia de produção.

\footnotetext{
6 Para detalhes, consultar Houck (1977), Carman e Sexton (2005) e Azevedo e Politi (2008).
} 
A elasticidade de transmissão refere-se à intensidade e ao período de ocorrência da transmissão de preço. A intensidade da transmissão é obtida por meio da elasticidade de transmissão de preços, ou seja, o impacto percentual da variação do preço em um segmento do sistema agroindustrial sobre a variação de preço do outro segmento. Uma elasticidade unitária implica que os preços estão sendo transmitidos na mesma proporção de sua alteração original. Portanto, nesse caso, a transmissão pode ser interpretada como um indicativo de uma distribuição equânime de ganhos proporcionados pelo aumento do preço do produto final da cadeia.

Quando a elasticidade de transmissão de preços é inferior à unidade, a transmissão é imperfeita. Nesse caso, essa medida indica a possibilidade de existência de exercício de poder de mercado. Essa inferência ganha peso quando a matéria-prima tem grande participação nos custos totais da indústria processadora; bem como quando não há alteração muito significativa na tecnologia, o que poderia elevar os custos do processamento, induzindo a uma transmissão assimétrica temporária.

\section{Metodologia}

A metodologia utilizada para análise das margens e da transmissão de preços implica na construção de séries de preços e no uso de um modelo econométrico. A metodologia utilizada para a construção das séries de preços é apresentada na seção 3.1, enquanto o modelo econométrico é descrito na seção 3.2.

\subsection{Construção das séries de preços}

Para a análise das margens de comercialização da indústria de suco de laranja é necessário obter séries de preços que o citricultor recebe pela laranja vendida e séries de preços recebidos pela indústria de processamento pelos sucos e subprodutos vendidos. Para os preços recebidos pela laranja destinada à indústria há duas séries men- sais publicamente disponíveis: a do Cepea (Centro de Estudos Avançados em Economia Aplicada) e a do IEA (Instituto de Economia Agrícola). A série do Cepea refere-se a valores médios pagos ao citricultor, a prazo, sem contrato, em $\mathrm{R} \$ / \mathrm{cx}$ de $40,8 \mathrm{~kg}$, posto na indústria paulista (custos da colheita e do frete inclusos). A série do IEA refere-se também a valores médios pagos pela indústria paulista ao citricultor, incluindo não apenas transações spot, mas também transações realizadas por meio de contratos. Deve-se atentar que, na década de 2000 , cerca de $70 \%$ da área colhida com laranja no Brasil encontrava-se no estado de São Paulo (IBGE, 2011). Na safra 2009/2010, 86\% da produção de São Paulo e do Triângulo Mineiro foi destinada ao processamento (NEVES, 2010).

Quanto aos preços recebidos pela indústria de suco na venda de seus produtos, não há informações disponíveis, exceto os dados mensais do MDIC (Ministério do Desenvolvimento, Indústria e Comércio Exterior) (2011) sobre quantidade e valor de exportação. Dividindo-se o valor de exportação pela quantidade exportada, obtém-se o preço médio de exportação ${ }^{7}$. Considerando-se que a produção de suco de laranja no Brasil destina-se majoritariamente às vendas internacionais, o preço médio de exportação pode ser considerado uma boa aproximação da evolução do preço recebido pela indústria.

O preço médio de exportação de suco de laranja foi calculado a partir de dados disponíveis para os seguintes produtos e respectivos códigos NCM (Nomenclatura Comum do Mercosul): (a) suco de laranja concentrado e congelado, SLCC - (2009.11), (b) outros sucos concentrados de laranja (2009.19) e (c) suco de laranja não congelado, com valor Brix não superior a 20 (2009.12, em que se enquadra o NFC, not-from-concentrate). Dividindo-se o valor das exportações, informado em US\$, pela quantidade, obtém-se o preço médio de exportação em um determinado mês. Assume-se que os produtos declarados como 2009.11 e 2009.19 compreendem a totalidade do

7 Worth (1999) adotou o mesmo procedimento em estudo de transmissão de preços de produtos agrícolas nos Estados Unidos. 
SLCC exportado, enquanto os produtos declarados como 2009.12 compreendem a totalidade do NFC exportado.

A diferença entre os preços da laranja recebidos pelos produtores e o preço do suco recebido pela indústria revela a margem da indústria. Para que essa diferença seja tecnicamente coerente, é necessário obter os dois preços referenciados a uma única unidade de medida de quantidade e a uma única moeda de referência. A unidade de quantidade utilizada nesse estudo foi "libra de sólidos solúveis" e a moeda, o dólar americano.

Os preços da laranja são divulgados em Reais por caixa de 40,8 quilos. Para transformá-los em US\$ por libra de sólidos solúveis, deve-se obter o rendimento em libras de sólidos solúveis em cada caixa de laranja. Segundo Neves (2010), o rendimento industrial médio no Brasil de 1995 a 2009 foi de 238 caixas de laranja para se obter 1 tonelada de FCOJ 66 Brix. Segundo Florida Department Of Citrus, Economic and Market Research Department (2011, p. 45) e Neves (2010, p. 134), uma tonelada métrica de SLCC a 66 Brix contém 1.455 libras de sólidos. Dividindo-se essa última quantidade pelo número de caixas necessárias para obtê-la, tem-se a quantidade de sólidos por caixa de laranja. Assim, em 238 caixas de laranja há 1.455 libras de sólidos. Logo, em uma caixa há 6,113445 libras de sólidos ${ }^{8}$. O preço em Reais por caixa é, então, convertido para Reais por libra de sólidos e, em seguida, convertido em US\$ por libra de sólido a partir da taxa de câmbio média do respectivo mês.

Os preços dos sucos são obtidos em US\$ por tonelada métrica. Portanto, para transformá-los em US\$ por libra de sólidos solúveis deve-se

${ }_{8}$ Em Neves (2010, p. 49), pode-se obter o rendimento industrial anual médio da caixa de laranja nas safras de 1988/89 a 2009/2010. Não há outras séries mensais publicamente disponíveis. Apesar dessa limitação, na construção das margens apresentadas no presente artigo, os preços da laranja por unidade de sólidos solúveis foram calculados a partir das médias anuais de rendimentos informados em Neves (2010). Entretanto, na análise de transmissão de preços adotou-se um único valor médio para todo o período. Essa restrição foi adotada porque a série de rendimentos disponível era anual, enquanto as séries de preços são mensais. obter a quantidade de libras de sólidos solúveis presentes em cada tonelada de suco. Para isso, foi utilizado o mesmo fator de conversão utilizado anteriormente - 1.455 libras de sólidos por tonelada métrica de 2009.11 ou 2009.19. O preço em US\$ por tonelada é então dividido por 1.455, obtendo-se o preço em US\$ por libra de sólidos para o SLCC. O NFC, entretanto, é mais diluído. Segundo Florida Department Of Citrus, Economic and Market Research Department (2011, p. 45-46), um galão de suco a 11,8 Brix (NFC) pesa 8,717 libras e contém 1,029 libras de sólidos. Uma tonelada equivale a 2.204,6 libras. Assim, em uma tonelada a 11,8 Brix, tem-se 260,2424 libras de sólidos. Essa é a quantidade de sólidos considerada para uma tonelada de NFC. O preço em US\$ por tonelada de NFC é, então, dividido por 260,2424, obtendo-se o preço em US\$ por libra de sólidos para o NFC.

Embora o SLCC e o NFC sejam os principais produtos vendidos pela indústria processadora no Brasil, não se pode descartar a receita obtida com a venda de subprodutos, especialmente o óleo essencial de laranja, farelo de polpa cítrica, d-limoneno e terpeno. Esses subprodutos são provenientes do processo de extração de suco da laranja. Nesse caso, torna-se fundamental considerar o valor recebido na venda dos mesmos no cálculo da margem da indústria. A quantidade e o valor das exportações desses subprodutos são também obtidos no MDIC (2011). Adicionando-se o valor das exportações de óleo essencial de laranja, farelo de polpa cítrica, d-limoneno e terpeno ao valor das exportações SLCC e NFC e dividindo-se pela quantidade equivalente de sólidos solúveis contidas nesses dois últimos, obtém-se a receita das empresas processadoras por libra de sólidos solúveis exportados.

Para a análise de transmissão de preços foram utilizadas séries mensais do preço da laranja (IEA) e do SLCC (2009.11 e 2009.19), de janeiro de 2000 a março de 2011. Para o exame gráfico das margens brutas, as séries mensais utilizadas abarcaram menor período de tempo em função da disponibilidade de dados para os rendimentos industriais, preços do NFC e subprodutos, cujos períodos são reportados nos gráficos. 
Deve-se atentar para o fato de que os valores das exportações de SLCC, NFC e subprodutos podem estar subestimados, pois existe a possibilidade de que os valores apresentados nas declarações das empresas no Sistema Integrado de Comércio Exterior (Siscomex) estejam subestimados, com o objetivo de obter ganhos fiscais. Além disso, não foram consideradas as vendas de subprodutos no mercado interno. Para essa última, não existem dados publicamente disponíveis. Em que pese essa limitação, deve-se atentar que, para a análise de transmissão de preços, utilizam-se as variações de preços.

\subsection{Modelo da transmissão de preços}

O modelo aplicado para verificar possíveis assimetrias na transmissão de preços dos processadores ao preço do produtor de laranja foi baseado nos trabalhos de Wolfram (1971), Houck (1977) e Worth (1999). Houck (1977) baseou-se no trabalho de Wolfram, criando um modelo de assimetria de preços, captado via segmentação da série original dos preços para períodos de variações positivas e negativas. Para ficar mais claro, considere que os preços recebidos pelos produtores de laranja do estado de São Paulo $\left(P P_{t}\right)$ dependam dos preços recebidos pela indústria processadora $\left(P I_{t}\right)$. Ao fazer uma análise no nível dessas variáveis, não será possível captar uma transmissão de preços segmentada, obtendo-se apenas uma elasticidade de transmissão de preços média para períodos em que os preços crescem e decrescem simultaneamente. Contudo, espera-se que, na presença de exercício de poder de mercado, haverá uma tendência da indústria em repassar em intensidades diferentes as variações em $P I_{t}$ para o produtor.

Considerando-se que as variações de $P P_{t}$ dependam das variações em $P I_{t}$ pode-se escrever a seguinte equação:

$$
\Delta P P_{t}=\beta_{0}+\beta_{1}^{+} \Delta P I_{t}^{a c}+\beta_{1}^{-} \Delta P I_{t}^{d c}+\varepsilon_{t}
$$

A segmentação do $P I_{t}$ é feita da seguinte maneira:

$$
\begin{aligned}
& \Delta P P_{t}=P P_{t}-P P_{t-1} \\
& \Delta P I_{t}^{a c}=\left\{\begin{array}{l}
P I_{t}-P I_{t-1}, \text { se } P I_{t}>P I_{t-1} \\
0, \text { caso contrário }
\end{array}\right. \\
& \Delta P I_{t}^{d c}=\left\{\begin{array}{l}
P I_{t}-P I_{t-1}, \text { se } P I_{t}<P I_{t-1} \\
0, \text { caso contrário }
\end{array}\right.
\end{aligned}
$$

Para os valores iniciais $P P_{0}$ e $P I_{0}$, pode-se denotar o preço ao produtor como:

$$
P P_{t}=P P_{0}+\sum_{t=1}^{T} \Delta P P_{t} \quad e \quad t=1,2, \ldots, T
$$

Essa equação mostra que a diferença entre o valor corrente do preço ao produtor e o preço inicial fixado em um instante de tempo qualquer é a soma das variações ocorridas de período a período. Portanto,

$$
P P_{t}-P P_{0}=\sum_{t=1}^{T} \Delta P P_{t}
$$

Substituindo-se a equação (1) em (6), ter-se-á o modelo proposto por Houck (1977) para análise da assimetria nos preços:

$$
\begin{aligned}
& P P_{t}-P P_{0}=\beta_{0} t+\beta_{1}^{+} \sum_{t=1}^{T} \Delta P I_{t}^{a c}+ \\
& +\beta_{2}^{-} \sum_{t=1}^{T} \Delta P I_{t}^{d c}+\varepsilon_{t}
\end{aligned}
$$

Considera-se os desvios dos preços ao produtor de laranja de um período $\mathrm{t}$ em relação ao período inicial $t=0$ como $V P P_{t}=P P_{t}-P P_{0}$; $\beta_{1} S A C=\beta_{1}^{+} \sum_{t=1}^{T} \Delta P I_{t}^{a c} ; \quad \beta_{2} S D C=\beta_{2}^{-} \sum_{t=1}^{T} \Delta P I_{t}^{d c}$. SAC e SDC são, respectivamente, os somatórios dos acréscimos e dos decréscimos nos preços da indústria processadora da laranja. Pode-se reescrever a equação (7) de forma simplificada:

$$
V P P_{t}=\beta_{0} t+\beta_{1} S A C+\beta_{2} S D C+\varepsilon_{t}
$$

Baseando-se em Houck (1977) para identificar se acréscimos e decréscimos de preços são transmitidos com a mesma intensidade ao produtor, deve-se testar $H_{0}: \beta_{1}=\beta_{2}$. Esse autor destaca que outras variáveis explicativas segmentadas ou não podem ser incluídas na equação (1).

Caso se rejeite a hipótese de que $H_{0}: \beta_{1}=\beta_{2}$, há assimetria. Se $\beta_{1}>\beta_{2}$, os acréscimos de preços são transmitidos mais intensamente que os decréscimos. Caso $\beta_{1}<\beta_{2}$, os decréscimos de pre- 
ços são transmitidos mais intensamente. Quando os preços forem transformados em logaritmos naturais, as elasticidades de transmissão serão os próprios coeficientes da equação estimada $\beta_{1} \mathrm{e}$ $\beta_{2}$. Para testar essas hipóteses foi aplicado o teste de Wald, cujo procedimento pode ser consultado em Greene (2007). Conforme Carman e Sexton (2005) e Azevedo e Politi (2008), é conveniente destacar que esse modelo permite analisar a simetria na transmissão de preços em momentos de queda e de elevações de preços, bem como a magnitude e a velocidade da transmissão de preços pela cadeia agroindustrial.

Para estimar a elasticidade de transmissão de preços de forma apropriada, as séries usadas na equação (8) devem ser estacionárias. Caso essas séries não sejam estacionárias, elas devem ser cointegradas para que não se tenham resultados espúrios (SEDDIGHI et al., 2000). Portanto, foram realizados testes de identificação de raiz unitária e de cointegração. Segundo Hamilton (1994), uma série temporal é fracamente estacionária ou estacionária na covariância se sua média, variância e covariância são constantes, independentemente do período de tempo em que sejam medidas. Após estimação do modelo econométrico, verificou-se a qualidade de seu ajustamento por meio dos seguintes testes ${ }^{9}: 1$ ) teste de normalidade; 2 ) teste de autocorrelação; 3) teste de heterocedasticidade condicional; 4) teste Reset Ramsey.

\subsection{Análise de causalidade nos preços de suco de laranja}

Para melhor compreensão das relações entre os preços ao produtor e os preços da indústria processadora de laranja e de como cada uma dessas cotações influencia a expectativa futura uma da outra, foram realizadas análises de causalidade, conforme Pindyck e Rubinfeld (2004). Para isso, os testes de causalidade de Granger foram aplicados, estimados a partir das equações:

9 Esses testes podem ser consultados em Hamilton (1994), Enders (1995), Gujarati (2011), Lütkepohl e Krätzig (2004), Greene (2007) e Bueno (2008).

$$
\begin{aligned}
& P P_{t}=\omega+\sum_{i=0}^{n} \theta_{i} P I_{t-i}+\sum_{j=1}^{p} \phi_{i} P P_{t-j}+v_{t} \\
& P I_{t}=\varphi+\sum_{i=0}^{n} \psi_{i} P P_{t-i}+\sum_{j=1}^{p} \pi_{i} P I_{t-j}+\vartheta_{t}
\end{aligned}
$$

em que $P P_{t}$ e $P I_{t}$ são, respectivamente, os preços pagos aos produtores de laranja e os preços recebidos pela indústria pelo produto final (suco de laranja); $\omega, \theta_{i}, \phi_{i}, \varphi, \psi_{i}, \pi_{i}$ são parâmetros a serem estimados; e, $v_{t}, \vartheta_{t}$ são erros aleatórios ruídos brancos. Há causalidade entre os preços analisados se pelo menos um dos coeficientes $\theta_{i}, \psi_{i}$ for estatisticamente diferente de zero em qualquer uma das duas equações. Há bicausalidade se o teste $\mathrm{F}$ for significativo nas duas equações, ocorrendo efeitos nas duas direções; não há causalidade, quando o teste $\mathrm{F}$ for não significativo nas duas equações; e há unicausalidade se o teste F for significativo em apenas uma equação.

\section{Resultados e discussão}

Nesta seção, apresentam-se as séries de preços, as margens e a análise de transmissão de preços, conforme proposto.

\subsection{Análise das margens}

A Figura 1 apresenta a evolução do preço recebido pelos produtores pela laranja (IEA) e os preços médios de exportação do SLCC e do NFC, todos convertidos para US\$ por libra de sólidos solúveis. A diferença entre os preços recebidos pelos produtores e os preços médios de exportação estabelece as margens brutas obtidas no processamento da laranja, tanto na venda de SLCC quanto na venda de NFC. Na Figura 2, essas margens foram calculadas em percentuais sobre $\mathrm{o}$ preço recebido pelo produtor de laranja ((preço médio de exportação - preço recebido pelo produtor)/preço recebido pelo produtor). Nota-se que, durante o período analisado, a margem obtida com a venda de SLCC foi positiva na maioria dos meses. As poucas exceções existentes não podem absolutamente ser assumidas como prejuízo para as processadoras, pois se deve considerar que a laranja é comprada majoritariamente de junho a 
dezembro, enquanto o suco estocado é vendido ao longo de todo o ano. Assim, mesmo quando libras de sólidos sob a forma de SLCC (preço recebido pela indústria) são exportadas com preço próximo ao preço de libras de sólidos sob a forma de laranja (preço recebido pelo citricultor), como nas safras de 2001 e 2005 (ver de junho a dezembro), a indústria é capaz de vender o estoque acu- mulado a preços superiores nos meses seguintes (ver de janeiro a maio de 2002 e 2006).

Nos dois casos, é notória a forte flutuação das margens. Além disso, as margens com NFC são visivelmente maiores do que aquelas alcançadas com SLCC. Considerando-se que a produção e a venda de NFC aumentaram significativamente desde o início da década analisada, pode-se assu-

Figura 1. Preço recebido pelo citricultor (IEA), preço médio de exportação de SLCC e preço médio de exportação de NFC, em US\$ por libra de sólidos solúveis, janeiro de 2001 a março de 2011

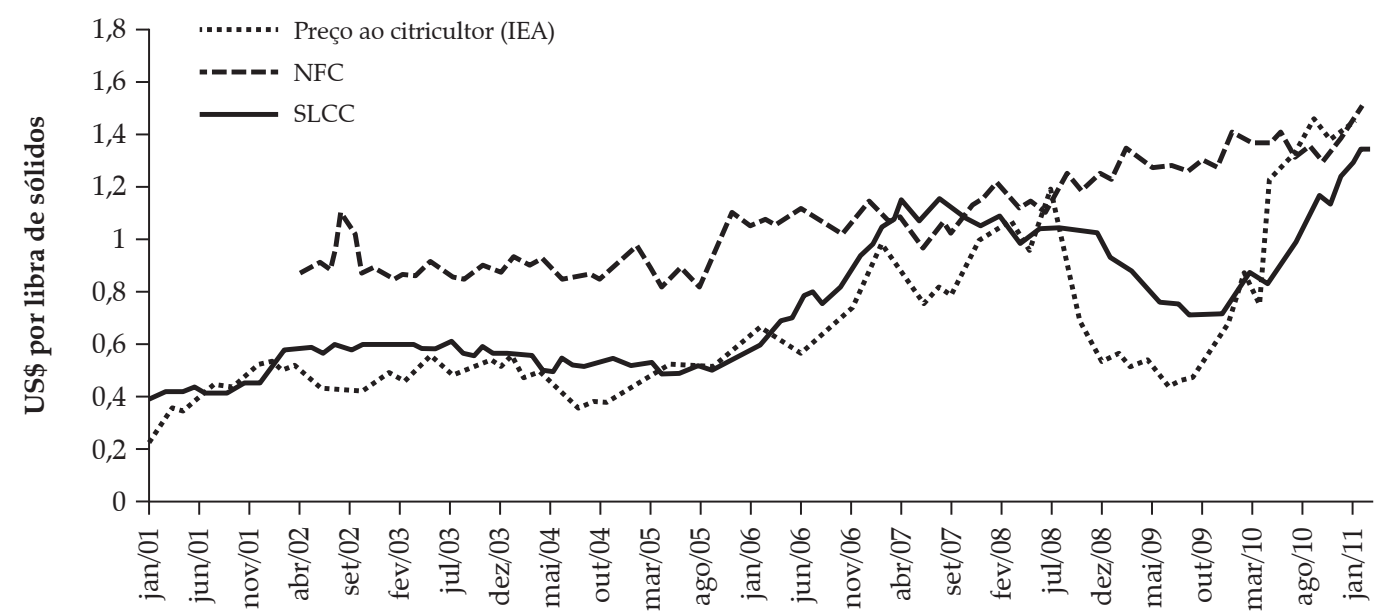

Fonte: Calculado a partir dos preços do IEA (2011) e dados do MDIC (2011).

Figura 2. Margens brutas do processamento, SLCC e NFC, janeiro de 2001 a março de 2011, em $\%$ sobre o preço ao produtor (IEA)

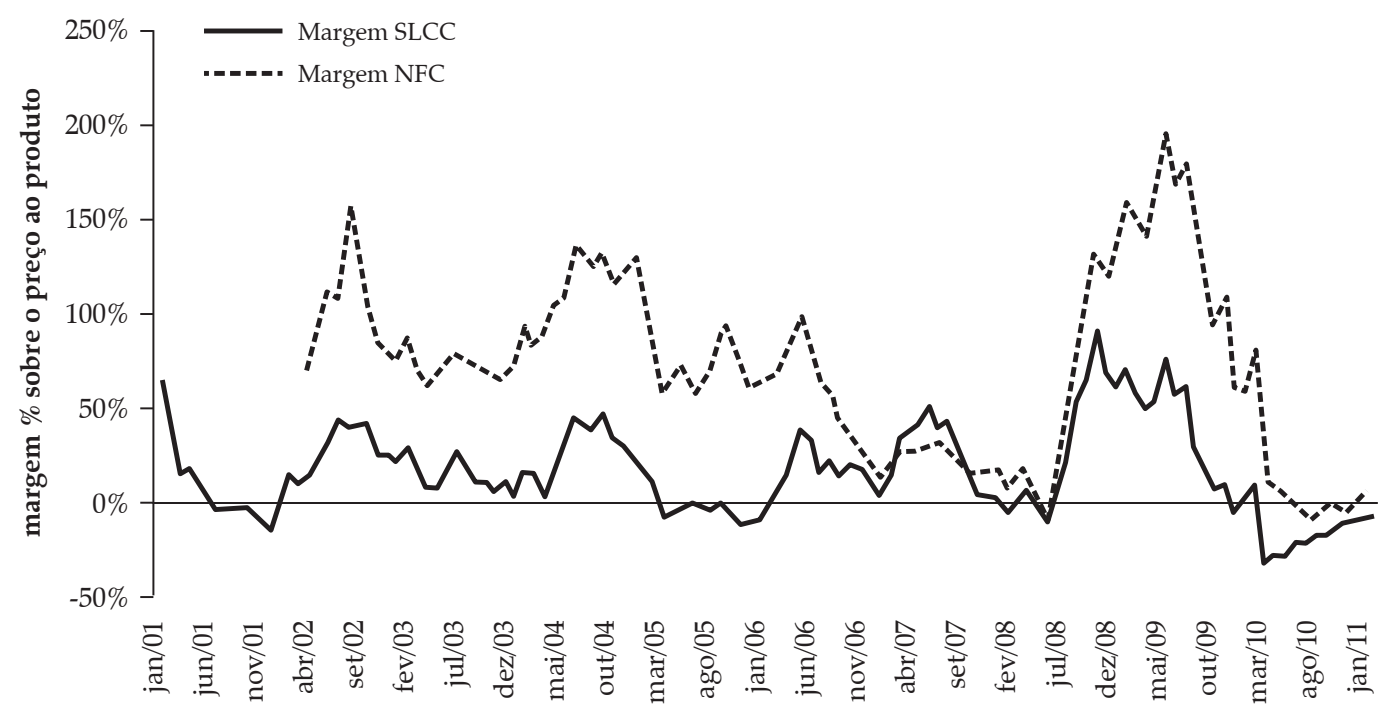

Fonte: Calculado a partir dos preços do IEA (2011) e dados do MDIC (2011). 
Figura 3. Preço recebido pelo citricultor (IEA), preço médio de exportação de SLCC + NFC e preço médio de exportação SLCC+NFC+subprodutos, janeiro de 2001 a novembro de 2010, em US\$ por libra de sólidos solúveis

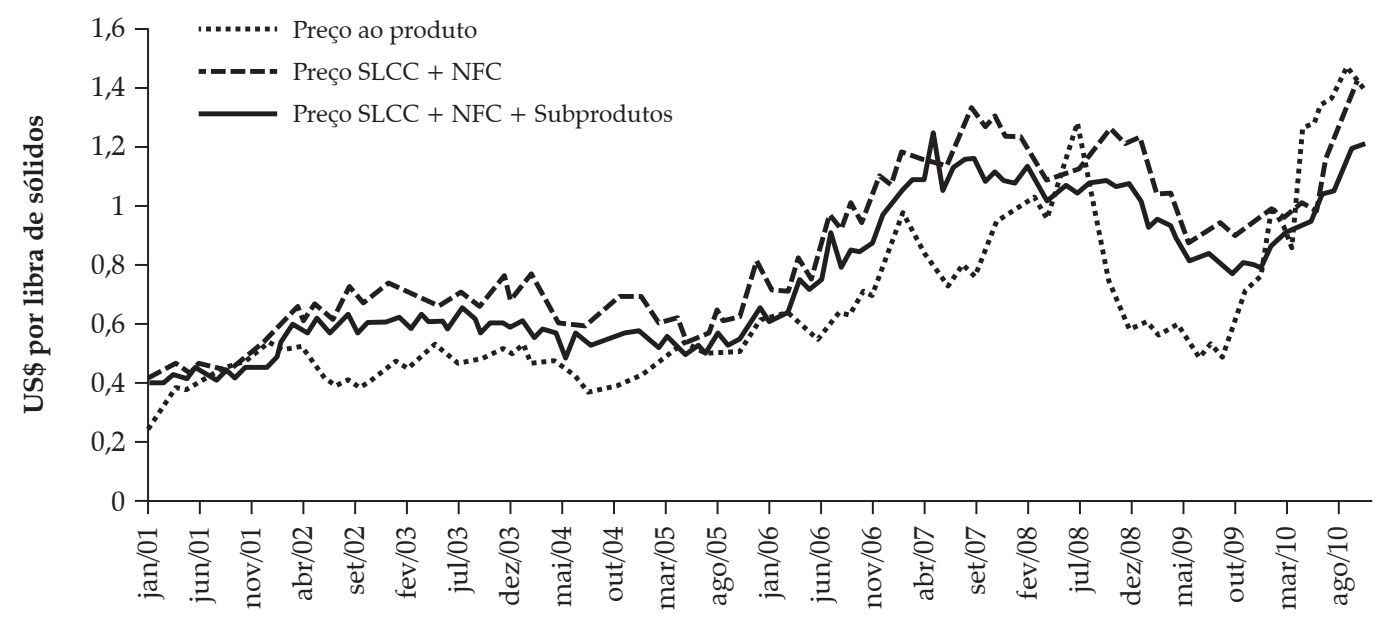

Fonte: Calculado a partir dos preços do IEA (2011) e dados do MDIC (2011).

Figura 4. Margem bruta do processamento, SLCC+NFC+subprodutos, janeiro de 2001 a novembro de 2010, em $\%$ sobre o preço ao produtor (IEA)

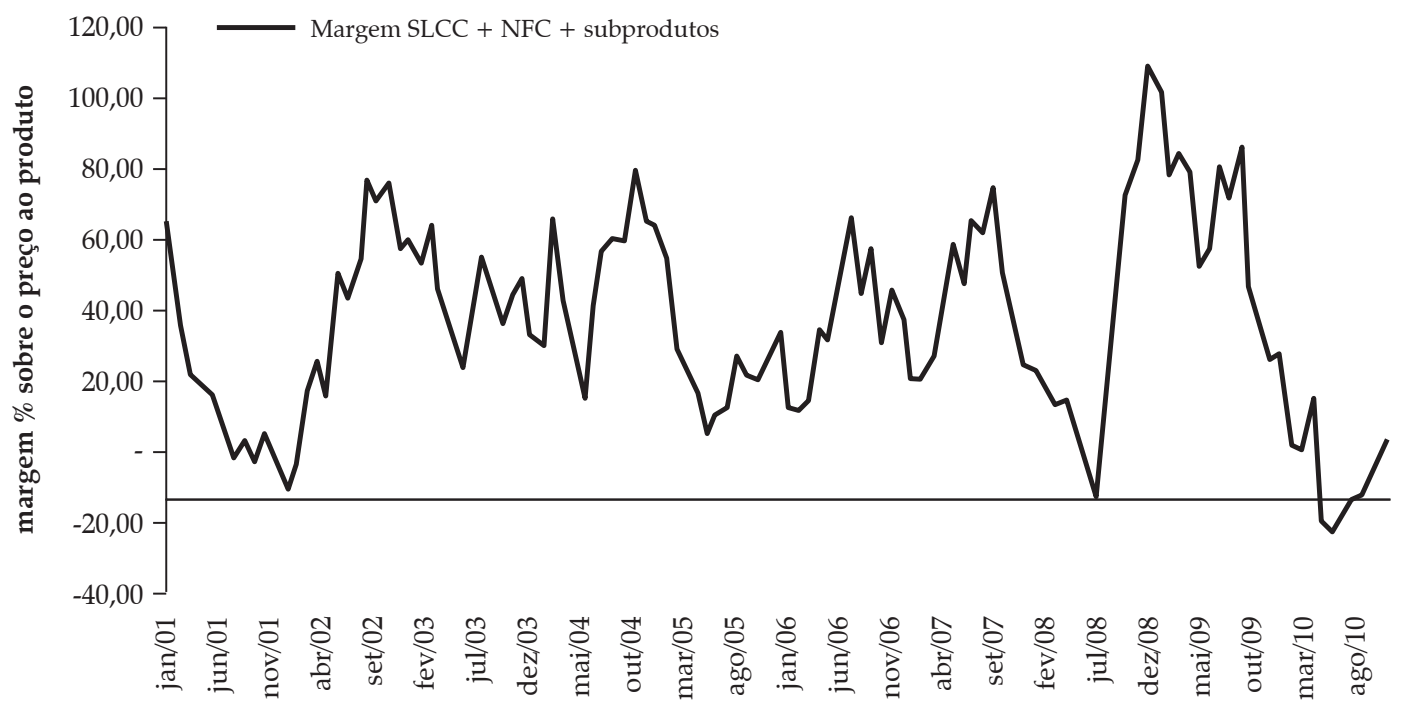

Fonte: Calculado a partir dos preços do IEA (2011) e dados do MDIC (2011).

mir que esse produto passou a ser importante para a formação das margens da indústria.

Na Figura 3, apresenta-se a evolução do preço médio de exportação do SLCC e NFC, conjuntamente, em dólares por libra de sólidos solúveis exportados. Como pode ser observado, a margem sobe significativamente, eliminando, inclusive, vários meses em que a margem seria suposta- mente negativa se apenas o SLCC fosse considerado. Denota-se, portanto, a importância que o NFC passou a assumir na agregação de valor da cadeia produtiva.

A Figura 3 apresenta também o preço médio de exportação quando a receita com exportações de subprodutos é adicionada à receita com SLCC e NFC. Nota-se que a margem aumenta em mon- 
tante não desprezível. Percebe-se que, embora o SLCC e o NFC sejam os principais produtos vendidos pela indústria processadora no Brasil, não se pode descartar a receita recebida com a venda de subprodutos na formação da margem da indústria brasileira de suco de laranja.

A Figura 4 apresenta a margem bruta, em percentagem sobre o preço recebido pelo produtor de laranja, obtida com suco e subprodutos. Como mencionado na metodologia, esse valor pode estar subestimado, pois não apenas não se considerou a possibilidade de subfaturamento nas declarações no Siscomex, como também não se considerou a venda de subprodutos no mercado interno. Em que pese essas limitações, nota-se que a margem das processadoras sobre o preço pago aos produtores eleva-se significativamente, ainda que se mantenha uma grande flutuação em torno de $40 \%$.

\subsection{Análise da transmissão de preços}

Foi realizada uma análise de transmissão de preços entre os dois estágios da produção aqui considerados. Nessa análise, foram utilizados os preços da laranja recebidos pelos produtores e os preços do suco recebidos pela indústria. A série de preços recebidos pelos produtores tem como fonte o Cepea/Esalq, que reflete os preços praticados no mercado spot de laranja para a indústria. Quanto à série de preços recebidos pela indústria, foram utilizados como proxy os preços médios de exportação dos sucos de laranja NCM 2009.11 (sucos de laranjas, congelados, não fermentados) e 2009.19 (outros sucos de laranjas, não fermentados), que correspondem ao SLCC. Deve-se considerar que as exportações de suco de laranja compreendem um elevado percentual da produção de suco vendida pelas empresas processadoras. Esses preços foram convertidos para dólares americanos por libra de sólidos solúveis, conforme exposto na seção 3.

Os preços são mensais, iniciando em janeiro de 2000 e finalizando em abril de 2011. Ao se trabalhar com essas séries surgiram dúvidas sobre a presença ou não de raiz unitária. Para resolver o impasse foram aplicados três testes para identificação de raiz unitária em cada série, sendo eles: ADF-GLS, KPSS e NG-PERRON. A partir dos resultados obtidos para esses três testes, considerou-se não estacionária a série que apresentou raiz unitária em pelo menos dois testes. Conforme as Tabelas 1A, 2A, e 3A do Apêndice A, pode-se inferir que as séries VPPt, SACt e SDCt são não estacionárias em nível, mas todas são estacionárias na primeira diferença, representada pela letra (d).

Segundo Seddighi et al. (2000), se as séries são integradas de mesma ordem, elas podem ser cointegradas. Caso as mesmas sejam cointegradas, um modelo entre elas pode apresentar resultados não espúrios. Portanto, os testes " $t$ " de Student e "F" de Fischer poderiam ser usados para inferências. Assim, foi feita uma análise de cointegração antes de se proceder a estimação do modelo de transmissão de preços. Para isso, foi aplicado o teste do traço de Johansen, cujos resultados, apresentados na Tabela 1, apontam para a existência de pelo menos um vetor de cointegração entre as variações dos preços ao produtor e os somatórios dos acréscimos e dos decréscimos de preços médios de exportação. Margarido et al. (2011) também detectaram um vetor de cointegração entre os preços médios de exportação de suco de laranja e preços recebidos pelo produtor de laranja para a indústria, embora tenham utilizado metodologia diferente do modelo de Houck.

Após análise de estacionariedade e cointegração, foram realizados testes de causalidade. Da análise de causalidade é possível inferir que, por um lado, não se rejeita a hipótese de que os acréscimos de preços da indústria não Granger causam variações nos preços ao produtor de laranja para nenhum dos lags de defasagem selecionados. Por outro, rejeita-se a hipótese de que os decréscimos nos preços da indústria não Granger causam variações nos preços ao produtor ao nível de significância de $10 \%$, para um lag de defasagem para os demais lags de defasagem esse efeito não foi significativo. Embora a análise de causalidade apenas indique se uma variável é importante 
Tabela 1. Resultados do teste traço de Johansen para cointegração entre a variação dos preços recebidos pelos produtores de laranja e os somatórios dos acréscimos e dos decréscimos de preços da indústria, no período de jan. de 2000 a mar. de 2011

\begin{tabular}{|c|c|c|c|c|c|}
\hline \multirow{2}{*}{$\begin{array}{c}\text { № de vetores de cointegração paradois } \\
\text { lags de defasagem }\end{array}$} & \multirow[b]{2}{*}{$\operatorname{Traço~}^{(1)}$} & \multicolumn{2}{|c|}{ Valores críticos } & \multicolumn{2}{|c|}{ Resultado } \\
\hline & & $5 \%$ & $1 \%$ & $5 \%$ & $1 \%$ \\
\hline 0 & 54,60 & 42,44 & 48,45 & $S$ & $S$ \\
\hline 1 & 11,32 & 25,32 & 30,45 & $\mathrm{~N}$ & $\mathrm{~N}$ \\
\hline 2 & 4,85 & 12,25 & 16,26 & $\mathrm{~N}$ & $\mathrm{~N}$ \\
\hline
\end{tabular}

(1) O teste traço foi realizado considerando os termos de tendência e de intercepto. Ademais, foram considerados dois lags de defasagem, conforme critérios de informação de Hannan Quinn e de Schwarz.

Fonte: Resultados da pesquisa.

Tabela 2. Resultados do teste de causalidade de Granger entre os preços ao produtor e da indústria de citros em São Paulo, no período de jan. de 2000 a mar. de 2011

\begin{tabular}{ccccc}
\hline \multicolumn{2}{c}{ Ausência de Causalidade } & \multirow{2}{*}{ Lags $^{(\mathbf{1})}$} & Estatística F & P-valor \\
\hline De & Para & 1 & 0,852 & 0,358 \\
Acréscimos preços da indústria & & 2 & 1,272 & 0,284 \\
& Variações dos preços & 3 & 0,818 & 0,486 \\
Decréscimos preços da indústria & ao produtor & $\mathbf{1}$ & $\mathbf{3 , 1 4 4}$ & $\mathbf{0 , 0 7 9}$ \\
& & 2 & 2,246 & 0,110 \\
\hline
\end{tabular}

Nota: (1) Os lags usados para realização do teste de causalidade foram obtidos das estimativas dos critérios de informação de Akaike (AIC), Schwarz (SC), Hannan Quinn (HQ), Final Prediction Error (FPE) e da estatística Log Likelihood Ratio (LR), conforme Tabela 6A em anexo.

Fonte: Resultados da pesquisa.

para a previsão da outra, é possível entender esse resultado como uma fraca evidência de que um decréscimo de preços da indústria é repassado em alguma proporção para o produtor nos períodos seguintes. Destaca-se que, em um mercado com estrutura competitiva, a hipótese nula deveria ser rejeitada em ambas as situações de acréscimo e decréscimo de preços. Todavia, nesse caso, só não se rejeita a hipótese quando ocorrem quedas de preços. Portanto, embora o teste de causalidade de Granger seja superficial, já é um indicativo de que acréscimos nos preços recebidos pela indústria não são repassados aos produtores de laranja, pois, baseando-se nesse teste só há variações estatisticamente significativas dos preços ao produtor quando os preços da indústria estão caindo. Margarido et al. (2011) testaram a existência de causalidade entre o preço recebido pelos produtores de laranja para indústria e o preço médio de exportação de suco de laranja e não rejeita a hipótese de que esse último não Granger causa o primeiro. Contudo, destaca-se que as séries utilizadas por esses autores não foram decompostas, seguindo o procedimento de Houck.

Os resultados do modelo de Houck para análise de transmissão de preços foram apresentados na Tabela 4A - no Apêndice A. Esse modelo apresentou uma estrutura autorregressiva e, por isso, empregou-se o método de Mínimos Quadrados Não Lineares em sua estimação. Destaca-se que o próprio Houck (1977) alertou que a decomposição da variável explicativa em dois componentes relativos aos seus acréscimos e decréscimos poderia elevar a autocorrelação. Esse aspecto é detectado por vários outros autores como: (a) Carman e Sexton (2005), que aplicaram o modelo de Houck para analisar os preços de leite no oeste dos Estados Unidos e identificaram autocorrelação em todas as equações estimadas, tendo sido necessário estimá-las novamente aplicando o 
procedimento iterativo de Cochrane-Orcutt; (b) Lass (2005) também identificou a presença de autocorrelação na análise de assimetria nos preços do varejo de leite em estados do nordeste dos Estados Unidos, aplicando o método de Máxima Verossimilhança nas estimações; no Brasil, Azevedo e Politi (2008), dentre outros, também identificaram autocorrelação serial no modelo de Houck para o sistema agroindustrial do leite.

Os resultados obtidos permitem inferir que os acréscimos de preços na indústria não são repassados ao produtor no exato momento em que ocorre a alteração positiva dos preços. Azevedo e Politi (2008) argumentam que o modelo de Houck pode apresentar correlação forte entre suas variáveis explicativas. Isso leva à presença de multicolinearidade nas estimações e tornam inconclusivos os testes em casos de rejeição da hipótese nula. Essa constatação pode ser uma justificativa para os efeitos das somas dos acréscimos $\left(S A C_{t}\right)$ não apresentarem significância estatística. Pode, ainda, justificar altas probabilidades exatas de rejeição da hipótese nula - p-valor de aproximadamente $11 \%$-, isto é, de que os efeitos defasados das somas dos acréscimos $\left(S A C_{t-2}\right)$ e dos decréscimos $\left(S D C_{t-2}\right)$ de preços da indústria não influenciam a variação dos preços recebidos pelos produtores de laranja $\left(V P P_{t}\right)$.

Os decréscimos de preços da indústria são repassados ao produtor no mesmo período em que ocorre a variação negativa, sendo esse coeficiente estatisticamente significativo a $10 \%$ de probabilidade. O coeficiente dos decréscimos dos preços da indústria, defasados em dois períodos, mostra uma variação contrária ao esperado, indicando que a indústria repassa uma queda de preços imediatamente à sua ocorrência aos produtores e depois de dois meses ela volta a recompor os preços dos produtores mesmo que haja quedas nos preços. Nesse caso, é importante observar que o repasse imediato dos decréscimos de preços é maior do que a recomposição realizada de forma defasada; sendo assim, o efeito líquido é de queda menos que proporcional dos preços ao produtor quando o preço da indústria cai.
Com o objetivo de estimar as diferenças na transmissão de preços nos períodos de safra, inseriu-se uma variável binária no modelo. Essa variável, denominada DS1, varia de forma que: a) DS1 = 1 em agosto, setembro, outubro, novembro e dezembro; e b) DS1 = 0 nos demais meses de cada ano (Tabela 4A - no Apêndice A). Pelos resultados obtidos, percebe-se que os sinais dos coeficientes para o período de safra são contrários ao esperado, pois, durante a safra, os preços dos produtores aumentam em períodos que os preços da indústria caem e diminuem quando os preços da indústria sobem. Nota-se que o sinal dos acréscimos de preços foi negativo, indicando que, quando os preços da indústria aumentam em 1\%, no período de safra, os preços ao produtor caem $0,21 \%$. Quando os preços da indústria caem $1 \%$, os preços ao produtor aumentam $0,30 \%$.

Quanto ao ajustamento do modelo, pode-se inferir que, de acordo com os testes LM e ARCH-LM, o modelo não apresenta autocorrelação nem heterocedasticidade condicional. Ademais, conforme teste de Jarque-Bera, não se rejeita a hipótese de normalidade dos resíduos do modelo estimado. Outros detalhes sobre convergência, qualidade do ajustamento e teste Reset para erros de especificação são apresentados na Tabela 5A do Apêndice A.

A simetria na transmissão de preços foi verificada por meio do teste de restrições de Wald. Os resultados são apresentados na Tabela 3. Com a inclusão das defasagens dos somatórios dos acréscimos e decréscimos de preços da indústria no modelo de transmissão, os resultados foram divididos em simetria de curto prazo e de longo prazo. A simetria de curto prazo refere-se ao teste de simetria na transmissão de preços no mesmo período em que os choques ocorrem. Já a simetria de longo prazo refere-se ao teste de simetria, considerando os efeitos no mesmo período e em períodos defasados. Testou-se, ainda, a simetria, considerando os efeitos dos acréscimos e dos decréscimos dos preços da indústria sobre a variação dos preços ao produtor no período de safra. 
Tabela 3. Elasticidades de acréscimo e de decréscimo de preços entre indústria e produtor, de curto e longo prazo, e os testes de simetria do produto analisado no período de jan. de 2000 a mar. de 2011

\begin{tabular}{|c|c|c|c|c|c|c|}
\hline \multirow{2}{*}{ Elasticidade de } & \multicolumn{3}{|c|}{ Efeito de Curto Prazo (CP) ${ }^{(a)}$} & \multicolumn{3}{|c|}{ Efeito de Longo Prazo (LP) ${ }^{(\mathfrak{b})}$} \\
\hline & Coeficiente & Valor $P$ & Simetria $C P$ & Coeficiente & Valor P & Simetria $L P$ \\
\hline Acréscimo & 0,045 & 0,821 & \multirow{2}{*}{$1,28^{\mathrm{ns}}$} & 0,319 & 0,113 & \multirow{2}{*}{$5,27^{* *}$} \\
\hline Decréscimo & 0,444 & 0,065 & & 0,066 & 0,065 & \\
\hline Acréscimo Safra & $-0,213$ & 0,043 & \multirow{2}{*}{$0,75^{\mathrm{ns}}$} & 0,105 & 0,043 & \multirow{2}{*}{$8,61^{*}$} \\
\hline Decréscimo Safra & $-0,308$ & 0,025 & & $-0,241$ & 0,025 & \\
\hline
\end{tabular}

* Significativo a $1 \% ; * *$ Significativo a $5 \%$; ** Significativo a $10 \%$.

(a) Na análise de simetria no $\mathrm{CP}$, apenas efeitos no mesmo período de tempo foram considerados.

(b) Elasticidade calculada considerando-se efeito defasado de dois meses.

Fonte: Resultados da pesquisa.

De acordo com os resultados apresentados na Tabela 3, no longo prazo, pode-se inferir que há assimetria significativa a $5 \%$ para todo o período analisado. Considerando-se efeitos distintos no período de safra, a assimetria torna-se ainda mais evidente, sendo significativa a $1 \%$ de probabilidade. Salienta-se que acréscimos nos preços da indústria têm repasse estatisticamente zero para os preços ao produtor no curto prazo, enquanto que os decréscimos são repassados de forma significativa, em uma proporção de $44,4 \%$ das flutuações negativas imediatas ou de curto prazo nos preços da indústria.

\section{Considerações finais}

Esse texto apresentou indícios de que as margens brutas da indústria de suco de laranja no Brasil são maiores do que aquelas reveladas por estimativas que considerem apenas a venda de suco (NEVES, 2010). Demonstrou também que há indícios do uso de poder de mercado por parte das empresas processadoras de suco de laranja no Brasil em suas negociações de compra de laranja junto a citricultores independentes.

As margens brutas foram inicialmente apresentadas para os dois principais produtos vendidos pela indústria de suco, o SLCC e o NFC, o que permitiu verificar grande flutuação no período analisado. Em seguida, realizou-se uma estimativa dos ganhos obtidos com a venda de subprodutos, que foi adicionada ao cálculo das margens. Percebeu-se que as margens aumentam de forma significativa com essa adição. Essa constatação tem implicações para estudos de margens em cadeias agroindustriais que, em geral, consideram apenas os produtos principais e, assim procedendo, subestimam as margens dos elos de processamento. Há também implicações para as negociações que são realizadas entre agentes de cadeias agroindustriais para o estabelecimento de mecanismos de precificação e distribuição do valor agregado. Ao não considerar os ganhos com a venda de subprodutos, os agentes podem estar subestimando o valor agregado e o lucro obtido no processamento agroindustrial.

A análise de transmissão de preços demonstrou indícios de exercício de poder de mercado, cujos resultados principais foram:

- Quando os preços do suco (recebidos pela indústria) estão caindo, há variações significativas dos preços da laranja (pagos aos produtores). Entretanto, não há variações estatisticamente significativas quando os preços do suco estão subindo.

- Acréscimos nos preços do suco têm repasse zero para os preços ao produtor no curto prazo, enquanto que os decréscimos são repassados de forma significativa, em uma proporção de $44,4 \%$ das flutuações negativas imediatas ou de curto prazo nos preços da indústria.

- Os decréscimos de preços da indústria são repassados ao produtor no mesmo período em que ocorre a variação negativa, sendo 
estatisticamente significativo a $10 \%$ de probabilidade.

- Os acréscimos nos preços do suco não são repassados ao produtor no exato momento em que ocorre a alteração positiva dos preços.

A análise dos decréscimos dos preços da indústria, defasados em dois períodos, mostra uma variação contrária ao esperado, indicando que a indústria repassa uma queda de preços imediatamente à sua ocorrência aos produtores e depois de dois meses ela volta a recompor os preços dos produtores. Nesse, caso é importante observar que o repasse imediato dos decréscimos de preços é maior do que a recomposição realizada de forma defasada. Sendo assim, o efeito líquido é de queda menos que proporcional dos preços ao produtor quando o preço da indústria cai.

\section{Referências bibliográficas}

AGUIAR, D. R. D. Conceitos e ferramentas para análise de preços agrícolas. $2^{\text {a }}$. Rio de Janeiro: FGV Management - Pós-Graduação Lato Sensu em Gestão Empresarial Estratégica em Agribusiness, 2004.

AGUIAR, D. R. D. e FIGUEIREDO, A. M. Poder de mercado no varejo alimentar: uma análise usando os preços do estado de São Paulo. Revista de Economia e Sociologia Rural, v. 49, p. 967-990, 2011.

AZEVEDO, P. F. Integração vertical e barganha. Tese de Doutoramento defendida na Faculdade de Economia Administração e Contabilidade, Departamento de Economia, USP, São Paulo, 1996.

AZEVEDO, P. F. e POLITI, R. B. Concorrência e estratégias de precificação no sistema agroindustrial do leite. Revista de Economia e Sociologia Rural, v. 46, n. 3, Brasília, jul./set. 2008.

BUENO, R. L. S. Econometria de séries temporais. São Paulo: Cengage Learning, 2008. 320p.

CARMAN, H. F. e SEXTON, R. J. Supermarket fluid milk pricing practices in the Western United States. Agribusiness, New York, v. 21, p. 509-530, 2005.

CONSELHO DOS PRODUTORES DE CANA-DEAÇÚCAR, AÇÚCAR E ÁLCOOL DOS ESTADO
DE SÃO PAULO. Manual de instruções. 5. ed., CONSECANA, Piracicaba-SP, 2006.

FDOC - FLORIDA DEPARTMENT OF CITRUS, ECONOMIC AND MARKET RESEARCH DEPARTMENT. Citrus Reference Book. University of Florida, Gainesville, jun. 2011. Disponível em: < https:// fdocgrower.box.com/shared/dt42f2c7kk\#/s/dt42f2c 7kk/1/76187836/802682972/1>. Acesso em: 5 out. 2011.

DICKEY, D. A. e FULLER, W. A. Likelihood ratio statistics for autoregressive time series with a unit root. Econometrica, v. 49, n. 4, 1981, p. 1057-1073.

ELLIOTT, G., ROTHENBERG, T. J. e STOCK, J. $\mathrm{H}$. Efficient tests for an autoregressive unit root. Econometrica, v. 64, 1996, p. 813-836.

ENDERS, W. Applied econometric time series. New York: John Wiley \& Sons, Inc. 1995, 433p.

FIGUEIREDO, A. M., SOUZA FILHO, H. M., GUANZIROLI, C. e VALENTE JUNIOR, A. S. Análise da Transmissão de Preços no Mercado Brasileiro de Castanha de Caju. Revista Econômica do Nordeste, v. 41, 2010.

GREENE, W. H. Econometric analysis. 6. ed. Saddle River, NJ: Pearson Prentice Hall, 2007. 1178p.

GUJARATI, D. N. e PORTER, D. C. Econometria Básica. 5 ed. Porto Alegre: McGraw Hill, 2011, 924p.

HAMILTON, J. D. Time series analysis. Princeton: Princeton University Press, 1994. 799p.

HOUCK, J. P. Na approach to specifying and estimating nonreversible functions. American Journal of Agricultural Economics, v. 59, n.3, 1977, p. 570-72.

IBGE - INSTITUTO BRASILEIRO DE GEOGRAFIA E ESTATÍSTICA. Sistema IBGE de Recuperação Automática (SIDRA). Disponível em: <http://www. sidra.ibge.gov.br/>. Acesso em: 12 nov. 2011.

JOHANSEN, S. Statistical analysis of cointegration vectors. Journal of Economic Dynamics and Control, v. 12, p. 231-254, 1988.

JOHANSEN, S. Cointegration in partial systems and the efficiency of single-equation analysis. Jornal of Econometrics, v. 52, n. 3, p. 389-402, 1992.

KWIATKOWSKI, D., PHILLIPS, P. C. B., SCHMIDT, P. e SHIN, Y. Testing the null hypothesis of stationarity against the alternative of unit root. Journal of Econometrics, v. 54, p. 159-178, 1992.

LASS, D. A. Asymmetric Response of Retail Milk Prices in the Northeast Revisited. Agribusiness, Wiley Periodicals, Inc., v. 21, n. 4, p. 493-508, 2005. 
LÜTKEPOHL, H. e KRÄTZIG, M. Applied time series econometrics. New York: Cambridge University Press, 2004. 323p.

NEVES, M. F. (Coord.). O retrato da citricultura brasileira. Markestrat, centro de Pesquisa e Projetos em Marketing e Estratégia, 2010.

MARGARIDO, M. A., GHILARDI, A. A. e OLIVEIRA, A. L. R. Análise sobre os mecanismos de transmissão de preços nos mercados de laranja. Analise e Indicadores do Agronegócio, Instituto de Economia Agrícola (IEA), v. 6, n. 4, Abr. 2011.

MAYORGA, R. O., KHAN, A. S., MAYORGA, R. D., LIMA, P. V. S. e MARGARIDO, M. A. Análise de transmissão de preços do mercado atacadista de melão do Brasil. Revista de Economia e Sociologia Rural, v. 45, n. 3, Brasília, jul./set. 2007.

MDIC - MINISTÉRIO DO DESENVOLVIMENTO, INDÚSTRIA E COMÉRCIO EXTERIOR. Análise das Informações de Comércio Exterior (ALICE). Disponível em: <http://aliceweb2.mdic.gov.br/>. Acesso em: 6 dez. 2011.

NG, S. e PERRO. Lag length selection and the construction of unit root tests with good size and power. Econometrica, v. 69, n. 6, 2001, p. 1519-1554.

PAULILLO, L. F. O. Agroindústria e citricultura no Brasil: diferenças e dominâncias. Rio de Janeiro: E-papers, 2006, 482p.
PAULILO, L. F. O. e ALMEIDA, L. M. A coordenação agroindustrial citrícola brasileira e os novos recursos de poder: dos políticos aos jurídicos. Organizações Rurais e Agroindustriais, v. 1, p. 58-74, 2009.

PAULILLO, L. F. O. Nova fusão no segmento processador de suco de laranja do complexo agroindustrial citrícola brasileiro: razões e consequências econômicas e sociais. Trabalho desenvolvido conforme solicitação da Associtrus (Associação Brasileira de Citricultores) junto a Universidade Federal de São Carlos (UFSCar), 2011.

PHILLIPS, P. C. B. e PERRON, P.Testing for unit root in time series regression. Biometrika, v. 75, 1988, p. 335-346.

PINDYCK R. S. e RUBINFELD D. L. Econometria: modelos e previsões. Rio de Janeiro: Campus-Elsevier, 2004.

SEDDIGHI, H. R., LAWLER, K. A. e KATOS, A. V. Econometrics: a practical approach. New York: Routledge, 396 p. 2000.

VIEIRA, A. C. Integração vertical, concentração e exclusão na citricultura paulista. São Carlos, 2003, 171 p. Tese (Doutorado em Engenharia de Produção) - Centro de Ciências Exatas e Tecnologia. Universidade Federal de São Carlos.

WORTH, T. The F.o.b. - Retail Price Relationship For Selected Fresh Vegetables. Vegetables and Specialities, ERS-USDA, Vol. 279, 1999. p. 26-31. 


\section{Anexos}

Tabela 1A. Resultados dos testes ADF-GLS para identificação de raiz unitária nas séries de preços ao produtor e preços da indústria, São Paulo, jan. de 2000 a mar. de 2011

\begin{tabular}{|c|c|c|c|c|c|c|c|c|}
\hline \multicolumn{9}{|c|}{ Variáveis em nível } \\
\hline \multirow{2}{*}{ Testes } & \multirow{2}{*}{ Lags $^{(1)}$} & \multirow{2}{*}{ Drift } & \multirow{2}{*}{$\mathrm{Tt}$} & \multirow{2}{*}{ t-stat } & \multicolumn{3}{|c|}{ Valores Críticos } & \multirow{2}{*}{ Tem RU? } \\
\hline & & & & & $1 \%$ & $5 \%$ & $10 \%$ & \\
\hline $\mathrm{VPP}_{\mathrm{t}}$ & 1 & $S$ & $\mathrm{~S}$ & $-2,750$ & $-3,540$ & $-2,997$ & $-2,707$ & $\mathrm{~S}$ \\
\hline SACt & 5 & S & $\mathrm{S}$ & $-2,879$ & $-3,545$ & $-3,001$ & $-2,711$ & $\mathrm{~s}$ \\
\hline SDCt & 0 & S & $\mathrm{S}$ & $-0,777$ & $-3,539$ & $-2,996$ & $-2,706$ & $\mathrm{~s}$ \\
\hline \multicolumn{9}{|c|}{ Variáveis em primeira diferença } \\
\hline $\mathrm{dVPPt}$ & 0 & $\mathrm{~S}$ & $\mathrm{~N}$ & $-7,429$ & $-2,582$ & $-1,943$ & $-1,615$ & $\mathbf{N}$ \\
\hline dSACt & 4 & S & $\mathrm{N}$ & $-1,899$ & $-2,583$ & $-1,943$ & $-1,615$ & $\mathbf{N}$ \\
\hline $\mathrm{dSDCt}$ & 2 & S & $\mathrm{N}$ & $-1,823$ & $-2,583$ & $-1,943$ & $-1,615$ & $\mathbf{N}$ \\
\hline
\end{tabular}

Nota: (1) para definição do número de lags usou-se o critério de informação de Schwartz.

Fonte: Resultados da pesquisa.

Tabela 2A. Resultados dos testes KPSS para identificação de raiz unitária nas séries de preços ao produtor e preços da indústria, São Paulo, jan. de 2000 a mar. de 2011

\begin{tabular}{|c|c|c|c|c|c|c|c|c|}
\hline \multicolumn{9}{|c|}{ Variáveis em nível } \\
\hline \multirow{2}{*}{ Testes } & \multirow{2}{*}{$\operatorname{Lags}^{(1)}$} & \multirow{2}{*}{ Drift } & \multirow{2}{*}{$\mathrm{Tt}$} & \multirow{2}{*}{ t-stat } & \multicolumn{3}{|c|}{ Valores Críticos } & \multirow{2}{*}{ Tem RU? } \\
\hline & & & & & $1 \%$ & $5 \%$ & $10 \%$ & \\
\hline $\mathrm{VPP}_{\mathrm{t}}$ & 9 & S & $\mathrm{S}$ & 0,072 & 0,216 & 0,146 & 0,119 & $\mathbf{N}$ \\
\hline SACt & 9 & S & S & 0,128 & 0,216 & 0,146 & 0,119 & $\mathrm{~S}$ \\
\hline SDCt & 9 & $S$ & S & 0,253 & 0,216 & 0,146 & 0,119 & $\mathrm{~S}$ \\
\hline \multicolumn{9}{|c|}{ Variáveis em primeira diferença } \\
\hline dVPPt & 0 & $S$ & $\mathrm{~N}$ & 0,104 & 0,739 & 0,463 & 0,347 & $\mathbf{N}$ \\
\hline dSACt & 6 & S & $\mathrm{N}$ & 0,086 & 0,739 & 0,463 & 0,347 & $\mathbf{N}$ \\
\hline $\mathrm{dSDCt}$ & 4 & S & $\mathrm{N}$ & 0,451 & 0,739 & 0,463 & 0,347 & $\mathbf{N}$ \\
\hline
\end{tabular}

Nota: (1) para definição do número de lags usou-se o critério de Newey West.

Fonte: Resultados da pesquisa. 
Tabela 3A. Resultados dos testes NG-PERRON para identificação de raiz unitária nas séries de preços ao produtor e preços da indústria, São Paulo, jan. de 2000 a mar. de 2011

\begin{tabular}{|c|c|c|c|c|c|c|c|c|}
\hline \multicolumn{9}{|c|}{ Variáveis em nível } \\
\hline \multirow{2}{*}{ Testes } & \multirow{2}{*}{$\operatorname{Lags}^{(1)}$} & \multirow{2}{*}{ Drift } & \multirow{2}{*}{$\mathrm{Tt}$} & \multirow{2}{*}{ t-stat } & \multicolumn{3}{|c|}{ Valores Críticos } & \multirow{2}{*}{ Tem RU? } \\
\hline & & & & & $1 \%$ & $5 \%$ & $10 \%$ & \\
\hline VPPt & 2 & $S$ & $\mathrm{~S}$ & $-2,483$ & $-3,420$ & $-2,910$ & $-2,620$ & $S$ \\
\hline SACt & 3 & S & $\mathrm{S}$ & $-2,156$ & $-3,420$ & $-2,910$ & $-2,620$ & S \\
\hline SDCt & 3 & $\mathrm{~S}$ & $\mathrm{~S}$ & $-1,303$ & $-3,420$ & $-2,910$ & $-2,620$ & $\mathrm{~S}$ \\
\hline \multicolumn{9}{|c|}{ Variáveis em primeira diferença } \\
\hline dVPPt & 0 & S & $\mathrm{N}$ & $-5,258$ & $-2,580$ & $-1,980$ & $-1,620$ & $\mathrm{~N}$ \\
\hline $\mathrm{dSACt}$ & 4 & S & $\mathrm{S}$ & $-1,674$ & $-3,420$ & $-2,910$ & $-2,620$ & S \\
\hline dSDCt & 11 & $\mathrm{~S}$ & S & $-0,808$ & $-3,420$ & $-2,910$ & $-2,620$ & S \\
\hline
\end{tabular}

Nota: (1) para definição do número de lags usou-se o critério MAIC.

Fonte: resultados da pesquisa.

Tabela 4A. Resultados da estimativa do modelo de transmissão de preços entre indústria e produtor de laranja no estado de São Paulo, no período de jan. de 2000 a mar. de 2011

\begin{tabular}{ccccc}
\hline Variável Dependente & \multicolumn{3}{c}{ Variação dos preços recebidos pelo produtor de laranja } \\
\hline Variável Explicativa & Parâmetros & Estimativa & Estatística " $t$ " & Valor $P$ \\
\hline Intercepto & $\beta_{0}$ & 0,9798 & 3,5548 & 0,0005 \\
SACt & $\beta_{1}$ & 0,0454 & 0,2269 & 0,8209 \\
SDCt & $\beta_{2}$ & 0,4443 & 1,8659 & 0,0645 \\
SACt-2 & $\beta_{1 \text { defasado }}$ & 0,3187 & 1,5961 & 0,1131 \\
SDCt-2 & $\beta_{2 \text { defasado }}$ & $-0,3779$ & $-1,6009$ & 0,1121 \\
DS1 ${ }^{*}$ & $\beta_{3}$ & $-0,2128$ & $-2,9325$ & 0,0040 \\
DS1xSAC & $\beta_{1 \text { safra }}$ & $-0,2132$ & $-2,0448$ & 0,0431 \\
DS1xSDC & $\beta_{2 \text { safra }}$ & $-0,3076$ & $-2,2646$ & 0,0254 \\
D10 & $\beta_{4}$ & 0,2001 & 3,2636 & 0,0014 \\
AR(1) & $\beta_{5}$ & 1,5081 & 16,2281 & 0,0000 \\
AR(2) & $\beta_{6}$ & $-0,7475$ & $-4,7694$ & 0,0000 \\
AR(3) & $\beta_{7}$ & 0,1477 & 1,5817 & 0,1164 \\
\hline
\end{tabular}

Nota: $\left(^{*}\right)$ DS1 é uma variável binária tal que: a) DS1 = 1 nos meses de agosto, setembro, outubro, novembro e dezembro; e, b) DS1 = 0 nos demais meses de cada ano. Portanto, visa captar variações nos preços no período de safra.

Fonte: Resultados da pesquisa.

Tabela 5A. Estatísticas de ajustamento do modelo de transmissão de preços apresentado na Tabela 3

\begin{tabular}{ccc}
\hline Estatísticas & Estimativas & Valor P \\
\hline Interações para convergência & 12 & \\
$\mathrm{R}^{2}$ ajustado & 0,955 & $\ldots$ \\
Teste F & 248,542 & 0,000 \\
Erro padrão da equação estimada & 0,115 & $\ldots$ \\
BIC & $-1,130$ & $\ldots$ \\
Teste JB & 1,540 & $\mathbf{0 , 4 6 3}$ \\
Durbin-Watson stat & 1,977 & $\ldots$ \\
Teste LM & 1,970 & $\mathbf{0 , 5 7 9}$ \\
Teste ARCH-LM & 3,666 & $\mathbf{0 , 3 0 0}$ \\
Teste RESET & 1,643 & $\mathbf{0 , 1 9 8}$ \\
RaizAR1/módulo & 0,810 & 0,810 \\
RaizAR2/módulo & $0,35-, 25 \mathrm{i}$ & 0,427 \\
RaizAR3/módulo & $0,35+, 25 \mathrm{i}$ & 0,427 \\
\hline
\end{tabular}

Fonte: Resultados da pesquisa. 
Tabela 6A. Seleção do número de defasagens do teste de Causalidade de Granger

\begin{tabular}{|c|c|c|c|c|c|c|}
\hline \multirow{3}{*}{$\begin{array}{c}\text { Variáveis endógenas } \\
\text { Período amostral } \\
\text { Lag }\end{array}$} & \multicolumn{6}{|c|}{$\mathrm{D}(\mathrm{SAC}) \mathrm{D}(\mathrm{SDC}) \mathrm{D}$ (VPPC) } \\
\hline & \multicolumn{6}{|c|}{ 2000M01 2011M03 } \\
\hline & $\log L$ & LR & FPE & AIC & $\mathrm{SC}$ & HQ \\
\hline 0 & 537,7230 & NA & $3,13 \mathrm{e}-08$ & $-8,765951$ & $-8,697000^{*}$ & $-8,737945$ \\
\hline 1 & 555,8832 & 35,12959 & $2,69 \mathrm{e}-08$ & $-8,916119$ & $-8,640313$ & $-8,804095^{*}$ \\
\hline 2 & 566,1234 & 19,30527 & $2,64 \mathrm{e}-08$ & $-8,936449$ & $-8,453790$ & $-8,740408$ \\
\hline 3 & 580,3354 & $26,09410^{*}$ & $2,43 e-08^{*}$ & $-9,021892 *$ & $-8,332378$ & $-8,741833$ \\
\hline 4 & 583,8695 & 6,314989 & $2,66 \mathrm{e}-08$ & $-8,932286$ & $-8,035919$ & $-8,568210$ \\
\hline 5 & 590,8318 & 12,09842 & $2,75 \mathrm{e}-08$ & $-8,898881$ & $-7,795660$ & $-8,450787$ \\
\hline 6 & 595,1919 & 7,362149 & $2,98 \mathrm{e}-08$ & $-8,822818$ & $-7,512742$ & $-8,290705$ \\
\hline 7 & 597,3158 & 3,481935 & $3,35 \mathrm{e}-08$ & $-8,710096$ & $-7,193166$ & $-8,093966$ \\
\hline 8 & 602,8910 & 8,865340 & 3,56e-08 & $-8,653950$ & $-6,930167$ & $-7,953803$ \\
\hline 9 & 612,0571 & 14,12481 & $3,58 \mathrm{e}-08$ & $-8,656673$ & $-6,726036$ & $-7,872508$ \\
\hline 10 & 616,5693 & 6,731433 & 3,89e-08 & $-8,583104$ & $-6,445612$ & $-7,714921$ \\
\hline 11 & 627,4147 & 15,64573 & 3,82e-08 & $-8,613355$ & $-6,269010$ & $-7,661155$ \\
\hline 12 & 635,3006 & 10,98859 & $3,94 \mathrm{e}-08$ & $-8,595092$ & $-6,043892$ & $-7,558874$ \\
\hline
\end{tabular}

Notas: * lags de defasagem selecionado, conforme critério de informação:

LR: sequential modified LR test statistic (each test at 5\% level)

FPE: Final prediction error

AIC: Akaike information criterion

SC: Schwarz information criterion

HQ: Hannan-Quinn information criterion

Fonte: Resultados da pesquisa. 
